\title{
Respiratory Function and Dysfunction in Parkinson-Type Neurodegeneration
}

\section{Michal POKUSA ${ }^{1,2}$, Dominika HAJDUCHOVA ${ }^{2}$, Tomas BUDAY ${ }^{2}$, Alzbeta KRALOVA TRANCIKOVA ${ }^{1,2}$}

${ }^{1}$ Biomedical Center Martin, Jessenius Faculty of Medicine in Martin, Comenius University Bratislava, Martin, Slovak Republic, ${ }^{2}$ Department of Pathophysiology, Jessenius Faculty of Medicine in Martin, Comenius University Bratislava, Martin, Slovak Republic

Received September 9, 2019

Accepted November18, 2019

\begin{abstract}
Summary
Parkinson's disease (PD) is most commonly manifested by the presence of motor symptoms. However, non-motor symptoms occur several years before the onset of motor symptoms themselves. Hallmarks of dysfunction of the respiratory system are still outside the main focus of interest, whether by clinicians or scientists, despite their indisputable contribution to the morbidity and mortality of patients suffering from PD. In addition, many of the respiratory symptoms are already present in the early stages of the disease and efforts to utilize these parameters in the early diagnosis of PD are now intensifying. Mechanisms that lead to the development and progression of respiratory symptoms are only partially understood. This review focuses mainly on the comparison of respiratory problems observed in clinical studies with available findings obtained from experimental animal models. It also explains pathological changes observed in non-neuronal tissues in subjects with PD.
\end{abstract}

\section{Key words}

Parkinson's disease • Respiratory dysfunction • Airway defence • Animal models • Molecular mechanisms

\section{Corresponding author}

Alzbeta Kralova Trancikova, Biomedical Center Martin, Jessenius Faculty of Medicine in Martin, Comenius University in Bratislava, Mala Hora 4D, Martin, 036 01, Slovak Republic. E-mail: alzbeta.trancikova@uniba.sk

\section{Introduction}

Parkinson's disease (PD) is currently the second most prevalent neurodegenerative disorder after Alzheimer's disease. It is manifested mainly by motor symptoms such as tremor, bradykinesia, postural instability, muscle rigidity and weakness due to the progressive loss of dopaminergic neurons. The presence of general motor dysfunction is associated with dopaminergic neuronal damage of substantia nigra pars compacta (SNpc) in advanced stages of PD (Braak et al. 2003). Beside progressive aggravation of motor dysfunction, there are specific non-motor symptoms, which are present in advance of several years (Simuni and Sethi 2008). Decreased quality of life in PD patients is related to the presence of "typical" motor symptoms along with constipation, indigestion, urinary retention, dysphagia, sleep problems and others.

In this review, we focus mainly on the processes which affect the respiratory system and are associated or directly caused by neurodegeneration of Parkinson-type. Breathing abnormalities have already been described by Jameson Parkinson in 1817 in his "An essay on the shaking palsy" (Parkinson 2002). In the early reports on morbidity and mortality in PD, pneumonia was a common cause of early death. More recent reports indicate that, although patient lifespan is improving with optimal medical management, pulmonary complications are still the most frequent cause of death. Beside quite well-known disturbances of airway defensive reflexes, the article points to problems of the upper airways, regulation of breathing, limited lung volumes etc., thereby highlighting the urgency of further clinical and basic research studies in this field. 
Description and analysis of symptoms observed in patients with PD is further complemented by data from animal models of PD and recent information about the molecular background of cellular damage in this type of neurodegeneration.

\section{Respiratory function and dysfunction in patients with $\mathbf{P D}$}

Patients suffering from PD, even in the early asymptomatic stages, describe a variety of symptoms of different severity associated with the respiratory system. They include dyspnea, upper airway symptoms or stridor. Little is known about general pathogenesis of these conditions, a majority of problems detected in PD are believed to be caused directly by neurodegeneration and its consequence - which is the lack of proper motor control (Torsney and Forsyth 2017). However, there are also some other mechanisms which will be further discussed.

Correct and specifically early diagnosis of respiratory problems in PD patients tends to be complicated mainly because of the progressive character of the disease and motor symptoms which usually cover problems with breathing or at least make them less bothering. Moreover, patients with PD have reduced exercise tolerance and therefore respiratory problems may not manifest as they would in otherwise healthy subjects. Finally, there is also an impaired perception of symptoms such as dyspnea. These are the reasons why PD patients are misdiagnosed as anxious or depressed (Weiner et al. 1978, Onodera et al. 2000, Torsney and Forsyth 2017).

\section{Airway defense processes}

Airway defense processes such as sneezing, coughing or expiration reflex require coordinated motor response to produce high thoracic pressure as a driving force for powerful expiration which removes the mucus and other potential hazards out of the airways (Korpáš and Tomori 1979). Insufficient airway protection is a risk factor for aspiration pneumonia, mainly, if the "cough" problem is associated with the "swallowing" problem frequently seen in PD. In addition to neuronal changes, dysphagia and deglutination problems in PD patients are a major cause of aspiration pneumonia, a significant source of morbidity and mortality (Shill and Stacy 2002). It is well documented that cough efficacy is significantly reduced already at a moderate stage of PD. The situation is similar to muscular dystrophy or amyotrophic lateral sclerosis when the maximum cough flow is similarly reduced (Suarez et al. 2002, Ebihara et al. 2003). PD is characterized by motor problems which considerably limit the efficacy of cough expulsions. One of the most prominent features contributing to this condition is a failure to energize muscles up to the level necessary to perform fast or ballistic movements characteristic for airway defensive reflexes. Described phenomenon is again explained by neural dysfunction, particularly in connection with motor control disorders observed by decreased dynamic parameters such as exhalation pressure in the mouth, electromyographic activity of the abdominal muscles and maximum cough flow. These parameters are affected mainly in the mild stages of the PD according to the Hoehn-Yahr scale (Fontana et al. 1998, Ebihara et al. 2003). Hoehn-Yahr scale is a scoring system from 1 to 5 that describes the stages of PD, with 5 being the most severe (Hoehn and Yahr 1967).

Slightly different is the correlation of the sensitive component of the cough reflex and disease progression. Cough reflex sensitivity measured by inhalation of aerosols with gradually increasing concentration of tussive substances reflects the threshold of the airway sensory nerves. Sensory afferent part of the cough reflex pathways seems to be affected in more advanced stages of PD (4-5 stages of Hoehn-Yahr scale), as documented by Ebihara $e t$ al. (2003). The same authors also confirmed a significant reduction in sputum secretion of local substance $P$ in patients with later stages of PD as a possible cause of decreased cough sensitivity (Ebihara et al. 2003). These results represent the first findings on peripheral dysfunctions recognized in respiratory dysfunctions associated with PD. Considering these findings, local physiological regulation in the respiratory system of patients with PD should be evaluated as a highly interesting area of research.

\section{Upper airway problems}

Bradykinesia and rigidity of the vocal cords, leading to dysarthria and hypophonia (soft speech) is common and can be considered a cardinal sign of PD. Moreover, up to $70 \%$ of PD patients, even in the asymptomatic stage, may suffer from upper airway obstruction (UAO). UAO is mostly manifested by stridor. It is a result of increased rigidity and fatigue of the thyroarytenoid muscles. It occurs more frequently in patients with a higher degree of motor symptoms, such as postural rigidity, bradykinesia and dorsal column arthrosis (Neu et al. 1967, Shill and Stacy 2002, Seccombe et al. 2011, Torsney and Forsyth 2017). Vincken et al. described 
two patterns of UAO. The first type referred to "respiratory flutter", with an occurrence of $78 \%$ in their study, is characterized by the superimposed rapid oscillation of the supraglottic structures and vocal cords (Vincken et al. 1984). The second type of UAO, with an incidence ranging from $22 \%$ to $82 \%$ of patients, is characterized by the delay in expiration as a result of irregular but sudden changes of the flow-volume loop, at times indicating a complete obstruction.

It is thought that UAO is a direct consequence of the dysfunction of basal ganglia that cause changes in respiratory muscle response to agonists and antagonists actions (Vincken et al. 1984, Hovestadt et al. 1989, Shill and Stacy 2002). Differences in these studies vary, depending on the number of recruited patients, administration or withholding of levodopa during the study, or because of the ever-better diagnosis of UAO. Several studies demonstrated the positive effect of antiparkinsonian treatment by levodopa and apomorphine (short-acting dopamine agonist) on UAO (Neu et al. 1967, de Bruin et al. 1993, Izquierdo-Alonso et al. 1994, Sabate et al. 1996, Herer et al. 2001). Currently, the incidence of $\mathrm{UAO}$ in PD patients is decreasing, possibly due to a significant improvement in the diagnosis of UAO, its treatment or more homogenous groups of patients used in studies (Izquierdo-Alonso et al. 1994, Torsney and Forsyth 2017).

\section{Obstructive and restrictive ventilatory disorders}

Early studies of airway dynamics in PD patients revealed lower airway obstructive defect similar to chronic obstructive pulmonary disease. It was considered to be a dominant ventilatory abnormality in PD (Obenour et al. 1972). Clinical manifestation of airway obstruction includes e.g. wheezing and decreased expiratory flow rate. However, due to advances in therapy, better patient characterization, and control for obstructive risk factors such as smoking, the obstructive ventilatory abnormality is now recognized to be less common.

On the other hand, pathological processes such as bradykinesia, dyscoordination, contraction and weakness of inspiratory muscles lead rather to the restrictive ventilatory dysfunction. The frequency of restrictive respiratory dysfunction in PD patients varies from $28 \%$ to $94 \%$, depending on the homogeneity in the studies, disease progression, or treatment with anti-parkinsonian drugs. Decreased chest wall compliance together with a tremor pattern of intercostal and scalene muscles and fatigue which appears early during repetitive muscle activities manifests in pulmonary function testing as a restrictive abnormality (Tzelepis et al. 1988). Reduced vital capacity, which is a cardinal sign of restrictive disorders, in turn, increases the perception of fatigue caused by ineffective oxygenation. Restrictive abnormalities are less responsive to dopaminergic therapy. Studies on the impact of levodopa on this type of respiratory problem vary considerably due to the different age of the patients, the progression and duration of the disease, and the variety of techniques for assessing respiratory complications (Weiner et al. 1978, Pal et al. 2007, Torsney and Forsyth 2017).

Ventilatory dysfunction is thought to reflect the primary pathology of PD and likely correlates with the development of motor symptoms such as falls and gait freezing but not tremor and bradykinesia. Partial correlation with the disease duration was also described (Paulson and Tafrate 1970, Bateman et al. 1981, Estenne et al. 1984, Sabate et al. 1996, De Pandis et al. 2002, Sathyaprabha et al. 2005, Wang et al. 2014). Nowadays, more attention is paid to the non-neuronal origin of respiratory dysfunction in PD patients. In this case, muscular function disorders, in particular weakness of the inspiratory muscles, are considered. Therefore, the emphasis is placed on the study of inspiratory muscles and their weakness as a typical respiratory symptom in these patients (Baille et al. 2018).

\section{Regulation of breathing - response to hypercapnia}

Patients suffering from PD also showed reduced ability to respond to hypercapnia. This phenomenon can be explained by the fact that already in the early stages of PD there is selective degeneration of dopaminergic neurons in the medulla and carotid body, with subsequent $\mathrm{CO}_{2}$ and/or $\mathrm{O}_{2}$ regulation (Seccombe et al. 2011). However, clinical studies in this matter are intensely discussed as they share conflicting evidence. Furthermore, in general, the presence of dyspnea, subjective experience of breathing discomfort, is a strong predictor of mortality, and a significant indicator of the patient's clinical course (Parshall et al. 2012). According to several studies, perception of dyspnea was significantly improved by levodopa, without improving general pulmonary functions, suggesting the central action of the drug (Weiner et al. 1978, Onodera et al. 2000, Seccombe et al. 2011). Although dopaminergic treatment has broad observed effects on respiration, the explicit effect remains controversial. The measurement results seem to be highly dependent on the duration and severity of the disease. It is 
suggested that with the progression of the disease and the subsequent loss of dopaminergic neurons in the middle cerebral region and basal ganglia, further neurodegenerative processes occur in the medulla, leading to impaired respiratory function and ventilation (Torsney and Forsyth 2017).

According to these results, it could be assumed that a specific type of pathogenesis should also be present at the level of airway tissues. Most research work on PD is focused on the central nervous system, the neuronal system of animal models or neuronal cell models due to the high vulnerability of dopaminergic neurons to toxic changes. However, cellular hallmarks of PD are not limited only to neuronal dopaminergic cells as mentioned above. Many studies document the pathological process is present also in non-neuronal tissue. A higher rate of cell death is associated with a progressive disorder of intracellular physiology and dysfunctions in energy metabolism and production of reactive oxygen species, vesicular transport, improper protein folding, subsequent reparation and degradation, which is commonly associated with protein aggregation (Nakagomi et al. 2008, Wang and Hay 2015, Nguyen et al. 2019). All these features are currently documented by many published articles focused on neurodegeneration mechanisms. Whether they are present in the respiratory system and whether their severity correlates with the severity of typical motor symptoms has never been studied. However, the importance of these pathological changes in non-neuronal systems altered in PD is worth the attention as they can represent early markers of PD and thus having promising clinical applications in the diagnostic process.

\section{Lessons learned from animal models of PD}

The use of animal models to study respiratory problems associated with PD has only recently emerged in the literature. Several 6-hydroxydopamine-induced (6-OHDA) rodent models were used in these studies. To our best knowledge, there is no study that would analyze respiratory functions in genetic models of PD in laboratory animals.

A significant positive correlation with clinical studies is apparent in experimental studies with induced neurodegeneration in neuronal population responsible for respiratory control. In general, the reduction in the number of dopaminergic neurons in the SNpc induced by the intrastriatal administration of 6-OHDA in animals is associated with a significant decrease in the number of neurons in respiratory control centers. Most of the research regarding this topic is focused on the response to $\mathrm{PaCO}_{2}$ in relation to central and peripheral chemoreception. Central chemoreception itself is tightly controlled by specific types of neurons localized in the brainstem (Feldman et al. 2003, Guyenet and Bayliss 2015, Oliveira et al. 2017, Oliveira et al. 2018). These include retrotrapezoid nucleus (RTN), locus coeruleus (LC), medullary raphe, hypothalamic orexinergic neurons and nucleus of the solitary tract (NTS) (Dean et al. 1989, Mulkey et al. 2004, Takakura et al. 2006, Oliveira et al. 2017).

Bilateral intra-striatal injection of 6-OHDA results in a decrease in the density of neuronal markers (NeuN) (Lima et al. 2018), the number of tyrosine hydroxylase positive (TH+) neurons (Tuppy et al. 2015) and catecholaminergic neurons (Oliveira et al. 2017). Furthermore, the number of catecholaminergic neurons varies in periaqueductal grey (PAG) regions, as well as projections between PAG and RTN neurons was also significantly reduced (Tuppy et al. 2015, Lima et al. 2018).

Physiologically, these animals exhibited a decrease in the tachypnoeic response to hypercapnia but not to hypoxia exposure, suggesting that respiratory deficits in the bilateral 6-OHDA rat PD model are very likely of central origin. In addition, a decrease in resting diaphragm muscle activity (DiaEMG) was observed. Similarly, there is a reduction in hypercapnia-induced DiaEMG, genioglossus (GGEMG) and abdominal (AbdEMG) frequencies, and GGEMG and AbdEMG amplitudes (Lima et al. 2018). These results suggest that respiratory problems in the 6-OHDA rat PD model are closely related to the down-regulation of neuronal populations responsible for the generation of the respiratory rhythm (Tuppy et al. 2015). Furthermore, this model of PD confirmed that there is an indirect pathway between SNpc and RTN neurons that pass through PAG region, with defects occurring exclusively in this neuronal pathway (Lima et al. 2018).

In relation to catecholaminergic neurons, a massive loss of these neurons was observed in SNpc $(86 \%)$ and $\mathrm{LC}(83 \%)$ regions in these animals. In the group of animals with a 6-OHDA-induced lesion in SNpc, the reduction in the ventilation response to hypercapnia was restored 60 days after induction of the PD phenotype, but this effect was not observed in animals with a lesion in LC region. In further experiments, where hypercapnia was induced either in the RTN or LC regions, an increase in cfos positive neurons was observed in the LC region, corresponding to the increased activity of these cells. 
A complete opposite effect - a decrease of c-fos positive neurons was observed in the hypercapnia induced in the RTN region. These results suggest that LC catecholaminergic neurons may be responsible for mediating chemoreceptor function in this PD model (Oliveira et al. 2017).

In another study using the model of bilateral intrastriatal injection of 6-OHDA, the authors focused on changes related to orexin neurons. These neurons are localized exclusively in the hypothalamus and are thought to be an important part of the regulation of the sleep-wake states (Sakurai 2007, Oliveira et al. 2018) and breathing (Williams et al. 2007, Williams and Burdakov 2008, Oliveira et al. 2018). The authors observed a significant decrease in the total number of orexinergic neurons as well as the number of orexinergic neurons projecting into the RTN. However, the number of $\mathrm{CO}_{2}$-activated orexinergic neurons remained unchanged during the dark phase of animal biorhythm. In PD-induced animals, a disturbed respiratory response to hypercapnia was observed during the dark phase in both awake and sleeping animals. These findings contrasted with the findings observed during the light phase. The authors, therefore, suggest that the degeneration of orexinergic neurons may lead to impaired chemoreceptor function in the dark phase (Oliveira et al. 2018).

Several studies have focused on respiratory function in the rat model of PD with a unilateral lesion in the SNpc induced by 6-OHDA. Unilateral damage of the nigrostriatal pathway by 6-OHDA administered to the correct middle anterior brain bundle (MFB) resulted in a slight increase in tidal volume during normoxia. Under hypercapnia conditions, the respiratory volume response is even more pronounced, the respiratory rate is reduced followed by enhanced minute ventilation as a response to $\mathrm{CO}_{2}$. However, norepinephrine levels remained unchanged, with specific changes affecting mainly dopamine and serotonin. These changes in neuromediators concentrations could be responsible for the breathing changes observed in this model. As a possible mechanism of different modulation of phrenic and hypoglossal reactions, the authors suggest the involvement of a modified mechanism of dopamine efflux and of serotonin and orexin during hypoxia (Andrzejewski et al. 2019).

Recent literature mentioned also one murine PD model based on bilateral administration of 6-OHDA into the striatum. A decrease in resting respiratory frequency was observed due to increased expiratory time and decreased hypercapnic ventilatory response was also described. Measurements focused on different respirationrelated parameters revealed a stiffened ribcage in these animals. This phenomenon of increased stiffness in the chest was accompanied by abnormal accumulation of collagen in the alveolar septum and airways. These data suggest that respiratory dysfunction in 6-OHDA-induced PD model is caused by neurodegeneration in "respiratory brainstem centers" and pathological processes which affect chest muscles and airways. Both central and peripheral processes interact contributing to PD-related respiratory disorders (Oliveira et al. 2019).

These studies using rodent PD models provide a clear signal that these models are able to recapitulate the respiratory defects associated with $\mathrm{PD}$. In addition, the results described above confirm a strong correlation between clinical findings and data obtained in animal models.

\section{Lessons from the peripheral tissue pathology associated with PD neurodegeneration}

Typical markers of PD pathology in the neuronal cells are already well summarized. Intracellular pathogenesis slightly varies from case to case according to the number of specific manifestations of a certain dysfunction. However, it is assumed that the dysfunction of mitochondria plays an integral role in intracellular pathogenesis (Park et al. 2018). The key processes associated with mitochondrial network degeneration include disruption of respiratory chain efficiency leading to higher reactive oxygen species (ROS) production (Perfeito et al. 2012), as well as the imbalance in fission/fusion processes of mitochondrial network (Park et al. 2018). Disruption of biomembrane dynamics is another common feature of neuronal pathogenesis that occurs in several types of neurodegenerative disorders including PD. Affected organelles include Golgi apparatus (Gonatas et al. 2006), endoplasmic reticulum (Guardia-Laguarta et al. 2014, Gomez-Suaga et al. 2018) and generally transport of the vesicles, which is underlined in particular by reduced dopamine release (Nemani et al. 2010). These intracellular conditions are supposed to present a risk for disruption of calcium homeostasis and an increase in oxidative stress, which usually results in unspecified protein damage with an increased demand for synthesis or reparation of misfolded proteins. This condition is closely related to the parallel increase of stress of endoplasmic reticulum, as well as metabolic and inflammatory disorders (Omura et al. 2013). 
Cytoplasmic aggregates of misfolded proteins are the strongest diagnostic markers of neurodegenerative disorders in neuronal cells (Braak et al. 2003). In the case of PD, specific Lewy bodies with prevalent aggregated $\alpha$ synuclein deposits were identified in humans in different tissue types. Recent studies provide more and more data on the broad distribution of aggregated forms of $\alpha$ synuclein in non-neuronal tissues. The most predisposed tissues alongside the nervous system are gastrointestinal tract in general, but they also include endocrine organs with surrounding adipose tissue, kidneys, urinary tract (Beach et al. 2010) and muscles (Askanas et al. 2000). In this respect, the lack of information about the presence of $\alpha$-synuclein aggregates in the respiratory system could encourage further research in this area. On the other hand, several phenomena recently observed in the tissues of the respiratory system correspond very well to cellular degeneration of neurons during PD pathogenesis.

In this context, abnormality in electrophysiology of smooth muscle has been demonstrated in a chronic murine model of PD (Rota et al. 2019). As mentioned above, common respiratory muscle weakness is also observed (Fontana et al. 1998, Ebihara et al. 2003). This phenomenon is only partially explained by the decreased activity of motor nerve fibers that are subject to neurodegeneration. However, neuromuscular junctions are characterized by relatively high expression of $\alpha$-synuclein. The physiological role of $\alpha$-synuclein in muscles is still unknown but are believed to have a stimulating effect on the parallel amyloid $\beta$ deposition as well as on de novo production of additional muscle fibers (Askanas et al. 2000).

In addition, in a toxic animal model of PD based on 1-methyl-4-phenyl-1,2,3,6-tetrahydropyridine (MPTP) administration, apoptotic mediators were also upregulated in skeletal muscle of mice (Erekat 2015). Further in vitro studies have revealed the catalytic effect of oxidative stress on these events (Hashimoto et al. 1999). Furthermore, strong $\alpha$-synuclein positivity has been documented in the vascular endothelium as well as in smooth muscle cells (Tamo et al. 2002). Again, the prominent role of $\alpha$ synuclein in this type of tissue is unknown, but, similarly to amyloid $\beta$, it has been suggested that overexpression of $\alpha$-synuclein in endothelial or smooth muscle cells is associated with higher levels of oxidative stress (Jahroudi et al. 1998).

In animal PD model based on subacute 6-OHDA administration, an increase in endothelial nitric oxide production (Antosova et al. 2017) along with pro- inflammatory prostaglandins and cytokines during the development of endothelial inflammation was observed. As expected, the accumulation of monocytes in the vascular endothelium was detected in this process ( $\mathrm{Fu}$ et al. 2017). Immune system stimulation was also observed as a consequence of the $\alpha$-synuclein aggregation in myenteric plexus of gastrointestinal tract when macrophages have penetrated the site of deposition but were unable to clear tissue from a misfolded $\alpha$-synuclein. All these findings provide a supportive explanation for the fact that systemic inflammation is present in PD patients (Phillips et al. 2013).

Although there is a critical lack of information on the local pathology of airway tissues, a corresponding pattern of neurodegenerative and obstructive diseases can be found. Data from the analysis of coincidence of chronic obstructive pulmonary disease (COPD) with PD show unequivocally high co-morbidity of both diseases (Li et al. 2015). Consistently, recently obtained data have revealed local changes of tissue morphology in the respiratory tract, which are parallel to PD-like neurodegeneration in animal model. In mice, with 6-OHDA administration to the striatum exposure, immunohistology analysis has proven constitutional change of lungs. A significantly higher proportion of collagen fibers in alveolar septa and airways was confirmed together with increased airway resistance, elastance and viscance (Oliveira et al. 2019). Chronic bronchitis in obstructive pulmonary disease is currently a well-documented fact with the critical role of increasing ROS production in the process of disease pathogenesis. In favor of the similarity of COPD to neurodegeneration, data provided from mitochondrial research confirm disruption of fission/fusion processes and higher levels of ROS production by damaged mitochondria (Boukhenouna et al. 2018). In a study by Weidner et al. (2018), the morphology of endoplasmic reticulum in patients with COPD was also found to be altered in comparison to healthy subjects. Conversely, not so high degree of similarity was observed with other organelles. The Golgi apparatus appears to be slightly smaller in the pulmonary fibroblasts of COPD patients (Golgi / nucleus ratio). This is in contrast to neurodegeneration where this organelle is fragmented and dispersed throughout the cell (Weidner et al. 2018).

\section{Conclusions}

In the context of PD, more and more attention is currently being paid to the study of early pathological changes. Non-motor symptoms of the disease occur much 
earlier than the onset of motor symptoms. In this context, attention is also dedicated to respiratory problems, which often manifest in the early stages of the disease and worsen with disease progression. In addition, in 2018, an Israeli team published a study describing breath test that can detect early stages of Parkinson's disease based on an electronic system for detecting volatile molecules in exhaled air (Finberg et al. 2018).

However, the precise mechanisms of respiratory system disorders in these patients are not fully elucidated and it represents a strong challenge for researchers to deepen the knowledge in this field. Very likely, these symptoms are consequences of combined pathogenic processes e.g. neurodegeneration affecting respirationrelated neurons at the central level combined with peripheral mechanisms such as stiffness of thorax, weakness of respiratory muscles, obstruction of the airways etc. We can learn a lot from experimental animal models that are well established and capable of reproducing the symptoms observed in PD patients. The second option is the use of cellular models themselves, which are already characterized in detail and thus represent an ideal model for studying changes at the molecular level. Also, we must not forget about studies on other nonneuronal tissues that could help identify the source of the higher or lower vulnerability of specific cell types to PD degeneration.

\section{Conflict of Interest}

There is no conflict of interest.

\section{Acknowledgements}

This work was supported by Scientific Grant Agency of Ministry of Education, Science, Research and Sport of the Slovak Republic and Slovak Academy of Sciences (Tuppy et al.) grant No. 1/0334/18; Research and Development Grant of Ministry of Health of the Slovak Republic No. 2018/10-UKMT-6 and by project "Center of Excellence for Research in Personalized Therapy (CEVYPET)", ITMS: 26220120053, co-funded from the EU sources and European Regional Development Fund.

\section{References}

ANDRZEJEWSKI K, BUDZINSKA K, KACZYNSKA K: Effect of 6-OHDA on hypercapnic ventilatory response in the rat model of Parkinson's disease. Physiol Res 68: 285-293, 2019. https://doi.org/10.33549/physiolres.933949

ANTOSOVA M, MOKRA D, PEPUCHA L, PLEVKOVA J, BUDAY T, STERUSKY M, BENCOVA A: Physiology of nitric oxide in the respiratory system. Physiol Res 66 (Suppl 2): S159-S172, 2017. https://doi.org/10.33549/physiolres.933673

ASKANAS V, ENGEL WK, ALVAREZ RB, MCFERRIN J, BROCCOLINI A: Novel immunolocalization of alphasynuclein in human muscle of inclusion-body myositis, regenerating and necrotic muscle fibers, and at neuromuscular junctions. J Neuropathol Exp Neurol 59: 592-598, 2000. https://doi.org/10.1093/jnen/59.7.592

BAILLE G, PEREZ T, DEVOS D, DEKEN V, DEFEBVRE L, MOREAU C: Early occurrence of inspiratory muscle weakness in Parkinson's disease. PLoS One 13: e0190400, 2018. https://doi.org/10.1371/journal.pone.0190400

BATEMAN DN, COOPER RG, GIBSON GJ, PEEL ET, WANDLESS I: Levodopa dosage and ventilatory function in Parkinson's disease. Br Med J (Clin Res Ed) 283: 190-191, 1981. https://doi.org/10.1136/bmj.283.6285.190-a

BEACH TG, ADLER CH, SUE LI, VEDDERS L, LUE L, WHITE III CL, AKIYAMA H, CAVINESS JN, SHILL HA, SABBAGH MN, WALKER DG, ARIZONA PARKINSON'S DISEASE C: Multi-organ distribution of phosphorylated alpha-synuclein histopathology in subjects with Lewy body disorders. Acta Neuropathol 119: 689-702, 2010. https://doi.org/10.1007/s00401-010-0664-3

BOUKHENOUNA S, WILSON MA, BAHMED K, KOSMIDER B: Reactive oxygen species in chronic obstructive pulmonary disease. Oxid Med Cell Longev 2018: 5730395, 2018. https://doi.org/10.1155/2018/5730395

BRAAK H, DEL TREDICI K, RUB U, DE VOS RA, JANSEN STEUR EN, BRAAK E: Staging of brain pathology related to sporadic Parkinson's disease. Neurobiol Aging 24: 197-211, 2003. https://doi.org/10.1016/S0197$\underline{4580(02) 00065-9}$

DE BRUIN PF, DE BRUIN VM, LEES AJ, PRIDE NB: Effects of treatment on airway dynamics and respiratory muscle strength in Parkinson's disease. Am Rev Respir Dis 148: 1576-1580, 1993. https://doi.org/10.1164/ajrccm/148.6_Pt_1.1576 
DE PANDIS MF, STARACE A, STEFANELLI F, MARRUZZO P, MEOLI I, DE SIMONE G, PRATI R, STOCCHI F: Modification of respiratory function parameters in patients with severe Parkinson's disease. Neurol Sci 23 (Suppl 2): S69-S70, 2002. https://doi.org/10.1007/s100720200074

DEAN JB, LAWING WL, MILLHORN DE: $\mathrm{CO}_{2}$ decreases membrane conductance and depolarizes neurons in the nucleus tractus solitarii. Exp Brain Res 76: 656-661, 1989. https://doi.org/10.1007/BF00248922

EBIHARA S, SAITO H, KANDA A, NAKAJOH M, TAKAHASHI H, ARAI H, SASAKI H: Impaired efficacy of cough in patients with Parkinson disease. Chest 124: 1009-1015, 2003.https://doi.org/10.1378/chest.124.3.1009

EREKAT NS: Apoptotic Mediators are Upregulated in the Skeletal Muscle of Chronic/Progressive Mouse Model of Parkinson's Disease. Anat Rec (Hoboken) 298: 1472-1478, 2015. https://doi.org/10.1002/ar.23124

ESTENNE M, HUBERT M, DE TROYER A: Respiratory-muscle involvement in Parkinson's disease. N Engl J Med 311 : 1516-1517, 1984. https://doi.org/10.1056/NEJM198412063112314

FELDMAN JL, MITCHELL GS, NATTIE EE: Breathing: rhythmicity, plasticity, chemosensitivity. Annu Rev Neurosci 26: 239-266, 2003. https://doi.org/10.1146/annurev.neuro.26.041002.131103

FINBERG JPM, SCHWARTZ M, JERIES R, BADARNY S, NAKHLEH MK, ABU DAOUD E, AYUBKHANOV Y, ABOUD-HAWA M, BROZA YY, HAICK H: Sensor Array for Detection of Early Stage Parkinson's Disease before Medication. ACS Chem Neurosci 9: 2548-2553, 2018. https://doi.org/10.1021/acschemneuro.8b00245

FONTANA GA, PANTALEO T, LAVORINI F, BENVENUTI F, GANGEMI S: Defective motor control of coughing in Parkinson's disease. Am J Respir Crit Care Med 158: 458-464, 1998. https://doi.org/10.1164/ajrccm.158.2.9705094

FU Q, SONG R, YANG Z, SHAN Q, CHEN W: 6-Hydroxydopamine induces brain vascular endothelial inflammation. IUBMB Life 69: 887-895, 2017. https://doi.org/10.1002/iub.1685

GOMEZ-SUAGA P, BRAVO-SAN PEDRO JM, GONZALEZ-POLO RA, FUENTES JM, NISO-SANTANO M: ERmitochondria signaling in Parkinson's disease. Cell Death Dis 9: 337, 2018. https://doi.org/10.1038/s41419-0170079-3

GONATAS NK, STIEBER A, GONATAS JO: Fragmentation of the Golgi apparatus in neurodegenerative diseases and cell death. J Neurol Sci 246: 21-30, 2006. https://doi.org/10.1016/j.jns.2006.01.019

GUARDIA-LAGUARTA C, AREA-GOMEZ E, RUB C, LIU Y, MAGRANE J, BECKER D, VOOS W, SCHON EA, PRZEDBORSKI S: alpha-Synuclein is localized to mitochondria-associated ER membranes. J Neurosci 34: 249 259, 2014. https://doi.org/10.1523/JNEUROSCI.2507-13.2014

GUYENET PG, BAYLISS DA: Neural control of breathing and $\mathrm{CO}_{2}$ homeostasis. Neuron 87: 946-961, 2015. https://doi.org/10.1016/j.neuron.2015.08.001

HASHIMOTO M, HSU LJ, XIA Y, TAKEDA A, SISK A, SUNDSMO M, MASLIAH E: Oxidative stress induces amyloid-like aggregate formation of NACP/alpha-synuclein in vitro. Neuroreport 10: 717-721, 1999. https://doi.org/10.1097/00001756-199903170-00011

HERER B, ARNULF I, HOUSSET B: Effects of levodopa on pulmonary function in Parkinson's disease. Chest 119: 387 393, 2001. https://doi.org/10.1378/chest.119.2.387

HOEHN MM, YAHR MD: Parkinsonism: onset, progression and mortality. Neurology 17: 427-442, 1967. https://doi.org/10.1212/WNL.17.5.427

HOVESTADT A, BOGAARD JM, MEERWALDT JD, VAN DER MECHE FG, STIGT J: Pulmonary function in Parkinson's disease. J Neurol Neurosurg Psychiatry 52: 329-333, 1989. https://doi.org/10.1136/jnnp.52.3.329

IZQUIERDO-ALONSO JL, JIMENEZ-JIMENEZ FJ, CABRERA-VALDIVIA F, MANSILLA-LESMES M: Airway dysfunction in patients with Parkinson's disease. Lung 172: 47-55, 1994. https://doi.org/10.1007/BF00186168

JAHROUDI N, KITNEY J, GREENBERGER JS, BOWSER R: Endothelial cell dysfunction in response to intracellular overexpression of amyloid precursor protein. J Neurosci Res 54: 828-839, 1998. https://doi.org/10.1002/(SICI)1097-4547(19981215)54:6<828::AID-JNR11>3.0.CO;2-M

KORPÁŠ J, TOMORI Z: Cough and Other Respiratory Reflexes. Karger, Basel vol. 12, 1979, p. 356.

LI CH, CHEN WC, LIAO WC, TU CY, LIN CL, SUNG FC, CHEN CH, HSU WH: The association between chronic obstructive pulmonary disease and Parkinson's disease: a nationwide population-based retrospective cohort study. QJM 108: 39-45, 2015. https://doi.org/10.1093/qjmed/hcu136 
LIMA JC, OLIVEIRA LM, BOTELHO MT, MOREIRA TS, TAKAKURA AC: The involvement of the pathway connecting the substantia nigra, the periaqueductal gray matter and the retrotrapezoid nucleus in breathing control in a rat model of Parkinson's disease. Exp Neurol 302: 46-56, 2018. https://doi.org/10.1016/j.expneurol.2018.01.003

MULKEY DK, STORNETTA RL, WESTON MC, SIMMONS JR, PARKER A, BAYLISS DA, GUYENET PG: Respiratory control by ventral surface chemoreceptor neurons in rats. Nat Neurosci 7: 1360-1369, 2004. https://doi.org/10.1038/nn1357

NAKAGOMI S, BARSOUM MJ, BOSSY-WETZEL E, SUTTERLIN C, MALHOTRA V, LIPTON SA: A Golgi fragmentation pathway in neurodegeneration. Neurobiol Dis 29: 221-231, 2008. https://doi.org/10.1016/j.nbd.2007.08.015

NEMANI VM, LU W, BERGE V, NAKAMURA K, ONOA B, LEE MK, CHAUDHRY FA, NICOLL RA, EDWARDS RH: Increased expression of alpha-synuclein reduces neurotransmitter release by inhibiting synaptic vesicle reclustering after endocytosis. Neuron 65: 66-79, 2010. https://doi.org/10.1016/j.neuron.2009.12.023

NEU HC, CONNOLLY JJ JR, SCHWERTLEY FW, LADWIG HA, BRODY AW: Obstructive respiratory dysfunction in parkinsonian patients. Am Rev Respir Dis 95: 33-47, 1967. https://doi.org/10.1164/arrd.1967.95.1.33

NGUYEN M, WONG YC, YSSELSTEIN D, SEVERINO A, KRAINC D: Synaptic, mitochondrial, and lysosomal

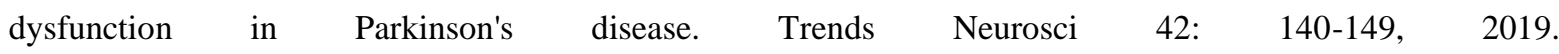
https://doi.org/10.1016/j.tins.2018.11.001

OBENOUR WH, STEVENS PM, COHEN AA, MCCUTCHEN JJ: The causes of abnormal pulmonary function in Parkinson's disease. Am Rev Respir Dis 105: 382-387, 1972. https://doi.org/10.1164/arrd.1972.105.3.382

OLIVEIRA LM, FALQUETTO B, MOREIRA TS, TAKAKURA AC: Orexinergic neurons are involved in the chemosensory control of breathing during the dark phase in a Parkinson's disease model. Exp Neurol 309: 107118, 2018. https://doi.org/10.1016/j.expneurol.2018.08.004

OLIVEIRA LM, OLIVEIRA MA, MORIYA HT, MOREIRA TS, TAKAKURA AC: Respiratory disturbances in a mouse model of Parkinson's disease. Exp Physiol 104: 729-739, 2019. https://doi.org/10.1113/EP087507

OLIVEIRA LM, TUPPY M, MOREIRA TS, TAKAKURA AC: Role of the locus coeruleus catecholaminergic neurons in the chemosensory control of breathing in a Parkinson's disease model. Exp Neurol 293: 172-180, 2017. https://doi.org/10.1016/j.expneurol.2017.04.006

OMURA T, KANEKO M, OKUMA Y, MATSUBARA K, NOMURA Y: Endoplasmic reticulum stress and Parkinson's disease: the role of HRD1 in averting apoptosis in neurodegenerative disease. Oxid Med Cell Longev 2013: 239854, 2013. https://doi.org/10.1155/2013/239854

ONODERA H, OKABE S, KIKUCHI Y, TSUDA T, ITOYAMA Y: Impaired chemosensitivity and perception of dyspnea in Parkinson's disease. Lancet 356: 739-740, 2000. https://doi.org/10.1016/S0140-6736(00)02638-6

PAL PK, SATHYAPRABHA TN, TUHINA P, THENNARASU K: Pattern of subclinical pulmonary dysfunctions in Parkinson's disease and the effect of levodopa. Mov Disord 22: 420-424, 2007. https://doi.org/10.1002/mds.21330

PARK JS, DAVIS RL, SUE CM: Mitochondrial Dysfunction in Parkinson's disease: New mechanistic insights and therapeutic perspectives. Curr Neurol Neurosci Rep 18: 21, 2018. https://doi.org/10.1007/s11910-018-0829-3

PARKINSON J: An essay on the shaking palsy. 1817. J Neuropsychiatry Clin Neurosci 14: 223-236; discussion 222, 2002. https://doi.org/10.1176/jnp.14.2.223

PARSHALL MB, SCHWARTZSTEIN RM, ADAMS L, BANZETT RB, MANNING HL, BOURBEAU J, CALVERLEY PM, GIFT AG, HARVER A, LAREAU SC, MAHLER DA, MEEK PM, O'DONNELL DE, AMERICAN THORACIC SOCIETY COMMITTEE ON D: An official American Thoracic Society statement: update on the mechanisms, assessment, and management of dyspnea. Am J Respir Crit Care Med 185: 435-452, 2012. https://doi.org/10.1164/rccm.201111-2042ST

PAULSON GD, TAFRATE RH: Some "minor" aspects of parkinsonism, especially pulmonary function. Neurology 20: 14-17, 1970. https://doi.org/10.1212/WNL.20.12_Part_2.14

PERFEITO R, CUNHA-OLIVEIRA T, REGO AC: Revisiting oxidative stress and mitochondrial dysfunction in the pathogenesis of Parkinson disease--resemblance to the effect of amphetamine drugs of abuse. Free Radic Biol Med 53: 1791-1806, 2012. https://doi.org/10.1016/j.freeradbiomed.2012.08.569 
PHILLIPS RJ, BILLINGSLEY CN, POWLEY TL: Macrophages are unsuccessful in clearing aggregated alpha-synuclein from the gastrointestinal tract of healthy aged Fischer 344 rats. Anat Rec (Hoboken) 296: 654-669, 2013. https://doi.org/10.1002/ar.22675

ROTA L, PELLEGRINI C, BENVENUTI L, ANTONIOLI L, FORNAI M, BLANDIZZI C, CATTANEO A, COLLA E: Constipation, deficit in colon contractions and alpha-synuclein inclusions within the colon precede motor abnormalities and neurodegeneration in the central nervous system in a mouse model of alpha-synucleinopathy. Transl Neurodegener 8: 5, 2019. https://doi.org/10.1186/s40035-019-0146-Z

SABATE M, GONZALEZ I, RUPEREZ F, RODRIGUEZ M: Obstructive and restrictive pulmonary dysfunctions in Parkinson's disease. J Neurol Sci 138: 114-119, 1996. https://doi.org/10.1016/0022-510X(96)00003-2

SAKURAI T: Regulatory mechanism of sleep/wakefulness states by orexin. Tanpakushitsu Kakusan Koso 52: 18401848, 2007.

SATHYAPRABHA TN, KAPAVARAPU PK, PALL PK, THENNARASU K, RAJU TR: Pulmonary functions in Parkinson's disease. Indian J Chest Dis Allied Sci 47: 251-257, 2005.

SECCOMBE LM, GIDDINGS HL, ROGERS PG, CORBETT AJ, HAYES MW, PETERS MJ, VEITCH EM: Abnormal ventilatory control in Parkinson's disease--further evidence for non-motor dysfunction. Respir Physiol Neurobiol 179: 300-304, 2011. https://doi.org/10.1016/j.resp.2011.09.012

SHILL H, STACY M: Respiratory complications of Parkinson's disease. Semin Respir Crit Care Med 23: 261-265, 2002. https://doi.org/10.1055/s-2002-33034

SIMUNI T, SETHI K: Nonmotor manifestations of Parkinson's disease. Ann Neurol 64 (Suppl 2): S65-S80, 2008. https://doi.org/10.1002/ana.21472

SUAREZ AA, PESSOLANO FA, MONTEIRO SG, FERREYRA G, CAPRIA ME, MESA L, DUBROVSKY A, DE VITO EL: Peak flow and peak cough flow in the evaluation of expiratory muscle weakness and bulbar impairment in patients with neuromuscular disease. Am J Phys Med Rehabil 81: 506-511, 2002. https://doi.org/10.1097/00002060-200207000-00007

TAKAKURA AC, MOREIRA TS, COLOMBARI E, WEST GH, STORNETTA RL, GUYENET PG: Peripheral chemoreceptor inputs to retrotrapezoid nucleus (RTN) CO2-sensitive neurons in rats. J Physiol 572: 503-523, 2006. https://doi.org/10.1113/jphysiol.2005.103788

TAMO W, IMAIZUMI T, TANJI K, YOSHIDA H, MORI F, YOSHIMOTO M, TAKAHASHI H, FUKUDA I, WAKABAYASHI K, SATOH K: Expression of alpha-synuclein, the precursor of non-amyloid beta component of Alzheimer's disease amyloid, in human cerebral blood vessels. Neurosci Lett 326: 5-8, 2002. https://doi.org/10.1016/S0304-3940(02)00297-5

TORSNEY KM, FORSYTH D: Respiratory dysfunction in Parkinson's disease. J R Coll Physicians Edinb 47: 35-39, 2017. https://doi.org/10.4997/JRCPE.2017.108

TUPPY M, BARNA BF, ALVES-DOS-SANTOS L, BRITTO LR, CHIAVEGATTO S, MOREIRA TS, TAKAKURA AC: Respiratory deficits in a rat model of Parkinson's disease. Neuroscience 297: 194-204, 2015. https://doi.org/10.1016/j.neuroscience.2015.03.048

TZELEPIS GE, MCCOOL FD, FRIEDMAN JH, HOPPIN FG, JR.: Respiratory muscle dysfunction in Parkinson's disease. Am Rev Respir Dis 138: 266-271, 1988. https://doi.org/10.1164/ajrccm/138.2.266

VINCKEN WG, GAUTHIER SG, DOLLFUSS RE, HANSON RE, DARAUAY CM, COSIO MG: Involvement of upperairway muscles in extrapyramidal disorders. A cause of airflow limitation. N Engl J Med 311: 438-442, 1984. https://doi.org/10.1056/NEJM198408163110704

WANG T, HAY JC: Alpha-synuclein toxicity in the early secretory pathway: how it drives neurodegeneration in Parkinsons disease. Front Neurosci 9: 433, 2015. https://doi.org/10.3389/fnins.2015.00433

WANG Y, SHAO WB, GAO L, LU J, GU H, SUN LH, TAN Y, ZHANG YD: Abnormal pulmonary function and respiratory muscle strength findings in Chinese patients with Parkinson's disease and multiple system atrophy-comparison with normal elderly. PLoS One 9: e116123, 2014. https://doi.org/10.1371/journal.pone.0116123

WEIDNER J, JARENBACK L, ABERG I, WESTERGREN-THORSSON G, ANKERST J, BJERMER L, TUFVESSON E: Endoplasmic reticulum, Golgi, and lysosomes are disorganized in lung fibroblasts from chronic obstructive pulmonary disease patients. Physiol Rep 6: e13584, 2018. https://doi.org/10.14814/phy2.13584 
WEINER WJ, GOETZ CG, NAUSIEDA PA, KLAWANS HL: Respiratory dyskinesias: extrapyramidal dysfunction and dyspnea. Ann Intern Med 88: 327-331, 1978. https://doi.org/10.7326/0003-4819-88-3-327

WILLIAMS RH, BURDAKOV D: Hypothalamic orexins/hypocretins as regulators of breathing. Expert Rev Mol Med 10: e28, 2008. https://doi.org/10.1017/S1462399408000823

WILLIAMS RH, JENSEN LT, VERKHRATSKY A, FUGGER L, BURDAKOV D: Control of hypothalamic orexin neurons by acid and $\mathrm{CO}_{2}$. Proc Natl Acad Sci U S A 104: 10685-10690, 2007. https://doi.org/10.1073/pnas.0702676104 